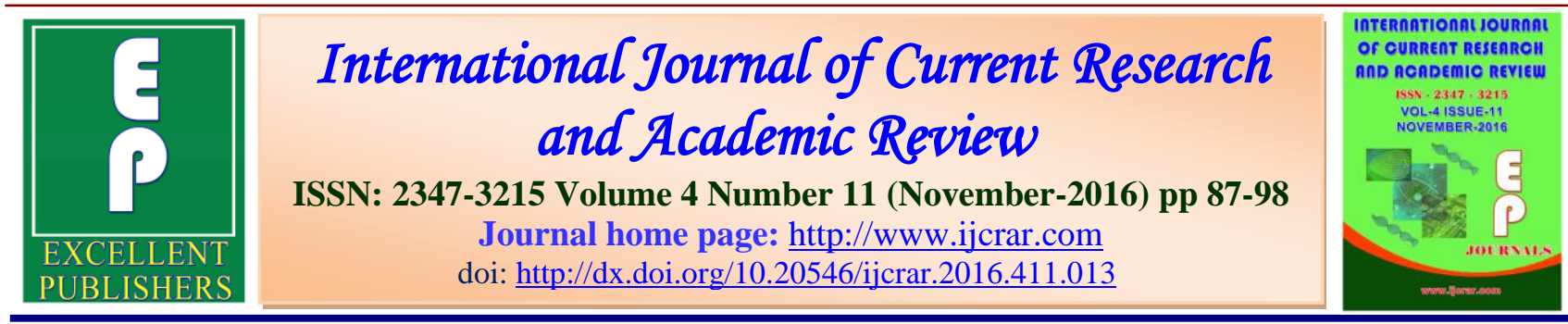

\title{
An Assessment of the Performance of Some Vegetable Markets and End Users in the Upper East Region of Ghana
}

\author{
A.D. Ninfaa ${ }^{1 *}$, D. Oppong-Sekyere ${ }^{1}$, A-R.S. Salifu ${ }^{1}$, B.B. Yintii ${ }^{1}$ and F.L. Manamzor ${ }^{2}$ \\ ${ }^{1}$ Department of Ecological Agriculture, Bolgatanga Polytechnic, P.O Box 767, Bolgatanga- \\ Ghana \\ ${ }^{2}$ Department of Marketing, Bolgatanga Polytechnic, P.O.Box 767, Bolgatanga-Ghana
}

\section{*Corresponding author}

\begin{tabular}{l|l}
\multirow{2}{*}{ KEYWORDS } & A B S T R A C T \\
\cline { 2 - 2 } & A
\end{tabular}

Aggregators, consumption, end users, storage, transportation, vegetable.
A study was undertaken in some selected districts in the Upper East Region of Ghana to assess aggregators and end users of vegetable in the region. Districts were selected based on their history of vegetable production. The Bawku municipality, Binduri district, Bolgatanga municipality, Bawku west and the Kassina Nankana west district qualified for selection. A purposive sampling method was used to select respondents for the study, and these were interviewed using a check list of questions, comprising both open and closeended questions, to gather information. The main aim of the research was to identify and assess the potentials of aggregators and end users of vegetables in the region. Hotels/ guesthouses, restaurants/chop bars and institutions (schools) were the selected end users for vegetables. These end users were categorized into 'very large', 'large' and 'medium', based on the number of guests/customers served food in a day. A total of fifty (50) aggregators, ten (10) from each district were selected and interviewed based on the volume of vegetables aggregated and sold, where their produce were sold, their prospective buyers, methods/facilities of storage, mode of transporting aggregated produce to the end user or storage point, the various challenges and relationships with the producer and end user regarding contracts. Data obtained from the checklist was analyzed using Statistical Package for the Social Scientists (SPSS version 17.0) and Microsoft Excel, and summarized into percentages and means. Tomatoes, Fresh okra, onion, Dry okra, cabbage, carrot, chilli pepper and sweet pepper were the commonly aggregated and consumed vegetables in the Upper East Region. Tomatoes and fresh Okra were the most aggregated and consumed vegetable by end users per an annual average of 27,090 kg, followed by onion $(26,418 \mathrm{~kg})$. Fresh tomatoes were the most consumed vegetable in the 'very large' category of end users, with annual consumption of $1,560 \mathrm{~kg}$ for guest house/Hotel and $8,736 \mathrm{~kg}$ for the restaurants/chop bars category. The restaurants/chop bars consumed the highest in terms of fresh tomatoes with a yearly consumption of $8,736 \mathrm{~kg}$. The tricycle, popularly called 'Motor king' in the study area was the most patronized $(30 \%)$ means of transporting aggregated vegetables to aggregation centers or end users. There is a higher prospect for vegetable business in the Upper East Region of Ghana, with the capacity of adequate supply across all regions of the country, in particular and the export market, in general. Actors in the value chain have to grapple with the constraints of finance and storage facilities. 


\section{Introduction}

The world today is dependent on agriculture for poverty reduction, food security and economic growth. According to Balarane and Oladele (2011), agriculture is the backbone of Africa's economy.

Tita (2008) has also stated that 86 percent of rural people depend on agriculture as a livelihood and provides jobs for about 1.3 billion smallholder farmers.

In Africa, most especially South Africa, the agricultural sector comprises the welldeveloped commercial farming (Antwi and Seahlodi, 2011), operated by few individuals mostly whites (Senyolo et al., 2009), and more subsistence-based production in the deep rural areas (Antwi \& Seahlodi, 2011) operated by black farmers (Senyolo et al., 2009).

Agriculture in Ghana, particularly the Upper East Region (UER) has long been based on subsistence farming where people derive their living from fragmented plots of land cultivated in difficult conditions. (MOFA, 2014)

The Upper East Region is highly recognized in terms of its vegetable production potentials in Ghana and its strategic linkages to Burkina Faso and Niger who are power houses in the production of vegetables especially onion.

The production of vegetables have been enhanced because of the availability of irrigation facilities and suitability of the climate to the production of vegetables especially onion.

Several people, especially females, are engaged in the marketing of vegetables in the region as a means of their livelihoods.
This trade has been enhanced because of the trends of market days in the region. A market day comes on a frequency of every three days.

Ideally, the trends are good for most farmers and marketers of the highly perishable vegetables. Onion, tomatoes, okro, green pepper, Chilli pepper, cabbage, carrots are among a host of vegetables produced in the region.

The vegetables are mostly sold in some bigger markets like the Bolgatanga, Bawku and the Navrongo markets.

Aggregators, who are the major players in this business, mostly offer support to farmers of these vegetables with inputs such as weedicides, pesticides, fertilizers, among others, to augment and facilitate their production. The farmers pay the services of the aggregators with produce and they, in return, sell to retailers in the market.

Institutions, Restaurants, Chop bars and Hotels are among the end users of these vegetables for the preparation of various dishes in the region.

Sadly, majority of the vegetables produced by farmers in the region are transported to markets in Kumasi, Accra, Techiman, Tamale, etc. for sale as they reportedly get better profit margins.

This research sought to identify the major vegetables marketed and consumed in the region, the various end users available and quantities consumed, the various storage methods used for these perishables, the marketing linkages involved as well as potential markets where producers can sell on credit, as it is a very common practice in the study area. 


\section{Materials and Methods}

\section{Study area}

The research was conducted in the Upper East Region. The Bawku Municipality, Kassina Nankana West, Binduri District, Bawku West and Bolgatanga Municipality were selected for the research based on their history of vegetable production, marketing potentials and the availability of irrigation facilities aiding all year round production and marketing.

\section{Research design}

The study used a descriptive research design. This was to ensure an objective conclusion on the relationship existing between the marketing and the various end users of vegetables in the Upper East Region. The study comprised data from both primary and secondary sources. The secondary data was collected from various institutions that regulate their activities. The primary data, was also gathered from respondents.

\section{Sampling method}

A purposive sampling method was used to select respondents for the study. The selected respondents were interviewed using a check list of questions to gather information. Each of the sets of checklist used comprised both open and close-ended questions to ensure detailed expressions by the respondents. The language of the checklist was very simple and straightforward eliciting the types of vegetables and quantities used and sold, storage methods employed and the various markets available for the sale of these vegetables.

Institutions (schools), Hotels/guest houses and Restaurants/chop bars were the various major end users identified for the study.
Heads of these identified categories were selected and interviewed based on their involvement in the purchase of vegetables.

The identified categories were further classified into 'very large', 'large' and 'medium'. Under the institution category, the following definitions were used;

\section{Institutions}

Secondary data on enrolment in institutions (Boarding schools) was collected from the Ghana Education Service, Bolgatanga.

These institutions were selected and considered for the study based on their usage of vegetable for food preparation.

\section{Categorization for institutions}

A "very large" end user of vegetables is defined as an institution with a student population of above two thousand (2000).

A "large" vegetable end user is an institution with a student population between 1500 to 2000 while a 'medium' end user is an institution with a student population of 1000 to 1499.

\section{Hotels/Guest houses}

Secondary data on registered hotels and guest houses were collected from the Ghana Tourist Board, Bolgatanga, and were also categorized into 'Very large', 'large' and 'medium'. A consideration was given to hotels and guest houses that prepare food for their guests.

\section{Categorization for hotels/guest houses}

A 'very large' hotel/guest house should have 30 beds and above, conference room with a seating capacity of 100 and above; receive 
guests almost every day, cook three or more times a day.

A 'large' hotel/guest house should have between 20-30 beds, conference room of a seating capacity of between $50-99$; receive guests almost every day and cook at least two times in a day while a 'medium' hotel/guesthouse should have between 10-19 beds, conference room of a seating capacity of between 40-49; receive guests almost every day and cook at least once a day for its guest.

\section{Restaurants/chop bars}

Secondary data on registered cop bars/restaurants was collected from the food and drugs Authority in Bolgatanga for the research. These were also categorized into 'Very large', 'large' and 'medium' restaurants and chop bars.

\section{Categorization of restaurants and guest houses}

A 'very large' chop bar should serve a minimum of 600 people in a day and prepare food three times in a day for customers.

A 'large' chop bar should serve at least 400 people in a day and prepare meals at least two times a day while a 'medium' restaurant/chop bar should serve at least 200 customers a day and cook at least once.

The above mentioned categories of end users were considered in order to help producers target and plan future potential markets for their vegetables. The concrete location of these end users were enough to serve as collateral to the producers and aggregators of vegetables, especially if a producer or an aggregator is contracted to sell on credit or is compelled by circumstances beyond the producer or aggregator's control, as it is very common in the study region. Individual end users were not targeted because of uncertainties regarding their location.

\section{Aggregators of vegetables}

For the purpose of this study, an aggregator is defined as an individual who serves as a middle man between a producers and end users.

The role of these aggregator were to buy the vegetables from the producers (farmers) and sell immediately or store and sell later. These aggregators were sampled and interviewed in the five selected districts/municipalities in the study area. A total of fifty (50) aggregators, ten (10) from each district were selected and interviewed based on the volume of vegetables aggregated and sold, where their produce were sold, their prospective buyers, methods/facilities of storage, mode of transporting aggregated produce to the end users or storage point, the various challenges and business relationships with the producers and end users regarding contracts.

\section{Data Analysis}

Data obtained from the checklist was analyzed using Statistical Package for the Social Scientists (SPSS version 17.0) and Microsoft Excel, and summarized into percentages and means where applicable.

\section{Results and Discussion}

Figure 1 shows that Tomatoes, Fresh okra, onion, Dry okra, cabbage, carrot, chilli pepper and sweet pepper were the commonly aggregated and consumed vegetables in the Upper East Region. The figure further shows that tomatoes and fresh Okra are the most aggregated and consumed 
vegetable by end users, recording the highest in annual average consumption of $27,090 \mathrm{~kg}$ and $27,000 \mathrm{~kg}$ respectively. This is followed by onion with an annual average of $26,418 \mathrm{~kg}$.

A study conducted by Danso et al., (2003) revealed that about $70 \%$ of the vegetables produced in Ghana is marketed and consumed fresh.

Vegetables are produced on a large scale in some parts of the country including the Upper East Region. Tomato, pepper and garden egg are the most popular vegetables in Ghana (Nkansah et al., 2002). This is confirmed by the current study.

Table.1 shows the monthly and yearly consumption of vegetables in the Upper East Region of Ghana for the 'very large' category of end users of the vegetables. Fresh tomatoes was the most consumed vegetable in the 'very large' category of end users, with annual consumption of $1,560 \mathrm{~kg}$ for Hotels/guest houses and 8,736kg for the restaurants/chop bars category. The restaurants/chop bars consumed the highest in terms of fresh tomatoes with a yearly consumption of $8,736 \mathrm{~kg}$.

Institutions (schools) did not used fresh tomatoes because of storage constraints. This confirms the findings of Kwarteng and Towler (1994) that, many agricultural produce are perishable; some of which deteriorate fast and have to be stored or processed to avoid spoilage.

The restaurants/chop bars consumed more because five (5) end users qualified under the category, while the institutions and hotels consumed lesser because each had two (2) end users per that category.
This finding goes to suggest that aggregators and even producers should target the restaurants/chop bars for the marketing of their vegetable produce.

\section{Monthly and annual demand for 'large' categories}

Table. 2 shows the yearly consumption of vegetables by the 'large' end user category in the Upper East Region of Ghana.

From the survey, fresh okra was consumed more by the restaurants/chopbars with an average annual consumption of $23,670 \mathrm{~kg}$; three restaurants/chop bars qualified under the 'large' category.

Institutions in the large category from the survey do not use fresh tomatoes in the preparation of their meals because they have aggregators and marketers who supply food items to them on credit; since tomatoes is very perishable, they are supplied canned tomatoes instead.

This is in line with the research findings of Kwarteng and Towler (1994). Their findings stated that agricultural produce have a short shelf life and that they deteriorate easily, thus demand appropriate storage and or processing to avoid deterioration and loss of revenue.

\section{Monthly and yearly demand for vegetable in the 'medium' end users}

Table.3 shows the monthly and yearly consumption of vegetables in the Upper East Region of Ghana by the 'medium' end users. Five (5) end users were identified in each category, an indication that the 'medium' category of end users was the majority in terms of the categorization. 
The most consumed vegetable was onion both for the hotel/guesthouse and the institutions categories recording an annual consumption of $4,380 \mathrm{~kg}$ in each case. The institutions category consumed more dry okra $(15,600 \mathrm{~kg})$. This is because the dry okra has a longer shelf life and easy to process into powder to serve large number of students in a meal. Aggregators of vegetables can target the 'medium' end users in the region because they are the majority group of consumers.

Transportation is a major challenge for most aggregators of vegetables. A research study by Matsane and Oyekale (2014) confirms the current results stating poor road networks and transportation as a major challenge militating against vegetable aggregation and marketing. The tricycle, Donkey cart and the trucks were the major means of transporting vegetables aggregated in the region. The tricycle, popularly called 'Motor king' in the study area was the most patronized $(30 \%)$ means of transporting aggregated vegetables to aggregation centers or end users.

Results in figure 3 revealed that market/room storage, market hats, warehouses and open storage were the commonly used storage methods adopted by aggregators and marketers.

Room storage was the commonly used storage method $(35 / 50)$ by aggregators and marketers of vegetables. This was followed by the use of market hats (10/50), open storage (4/50) and warehouses (1/50).

In Ghana, vegetables do not undergo any effective storage practices to improve their shelf life. Abbot (1984) affirmed that changes in perishable produce such as fruits and vegetables depend largely on storage temperature. Therefore it is necessary to permanently maintain the produce in appropriate conditions of temperature from time of harvest to the time of consumption to reduce postharvest losses and loss of revenue.

Results from the study as revealed by table 4 indicates that vegetables are aggregated in some districts and communities in the region (Bawku, Bazua, Navrongo and Zebila) and outside the region (Techiman and Burkina Faso). The aggregated vegetables, especially onion are mostly sold outside the region (Kumasi, Accra, Tamale etc.) due to relatively higher profit margins. Those vegetables aggregated outside the region (Techiman and Burkina Faso) are mostly sold in some popular markets (Bolgatanga, Bawku, Navrongo).These are made available by aggregators who are mostly women.

According to the result of the study (Figure 4), the most prevailing challenge of vegetable marketing in the Upper East region was inadequate storage facilities $(40 \%)$. This was followed by breach of trust $(24 \%)$, with inadequate credit facilities recording the last $(8 \%)$ in terms of the challenges.

A study by Matsane and Oyekale (2014) highlighting the factors (constrains) to vegetable production among small scale farmers in Mahikeng, South Africa corroborated the current study.

Kwarteng and Towler (1994), also affirmed the above factors.

\section{Conclusion}

The current study has proved to be most significant in identifying the various end users of onion and other vegetables as it pertains in the Upper East Region as; very 
large', 'large' and'medium'categories. The categories were created with stipulated criteria ranging from number of beds, seating capacity of conference room, number of times meals were prepared for guests (for the hotel/guest house and restaurants/chop bars groupings) to population size, frequency of meals prepared and number of bags used (for the institutional categorization). The categories indeed contributed significantly to the differences observed.

Nonetheless, the restaurants/chop bars consumed more per the five listed end users in the category with the same quantity of consumption while the institutions and hotels consumed lesser amounts. The observed differences in the current study was however evident in the consumption of vegetables depicted as follows; onion, cabbage, tomatoes, Chilli pepper, fresh okra, dry okra, sweet pepper, as vegetables commonly consumed in the Upper East region

The study proved positive for the use of dry okra mostly by the institutions, due to its longer shelf life. Similarly, the use of fresh tomatoes was not popular because they do not store longer; can tomatoes were the obvious choice.

Table.1 Total monthly and yearly demand for 'very large' end users

\begin{tabular}{|c|c|c|c|c|}
\hline Very Large category & Number & Vegetables & $\begin{array}{c}\text { Monthly } \\
\text { Volumes } \\
\text { (Kg) } \\
\end{array}$ & $\begin{array}{c}\text { Yearly } \\
\text { Volumes } \\
\text { (Kg) }\end{array}$ \\
\hline & & Onion & 146 & 1,752 \\
\hline & & Tomatoes & 130 & 1,560 \\
\hline & & Fresh Okra & 120 & 1440 \\
\hline & & Chili pepper & 24 & 288 \\
\hline & & Cabbage & 225 & 2700 \\
\hline & & Carrot & 200 & 2400 \\
\hline & & Sweet pepper & 102 & 1224 \\
\hline Guest Houses/Hotel & 2 & & & \\
\hline \multirow[b]{3}{*}{ Restaurants/chop bars } & \multirow[b]{3}{*}{5} & Onion & 366 & 4,380 \\
\hline & & Tomatoes & 728 & 8,736 \\
\hline & & Chilli Pepper & 24 & 288 \\
\hline \multirow[b]{3}{*}{ Institutions } & \multirow[b]{3}{*}{2} & Dry Okra & 120 & 1,440 \\
\hline & & Chilli pepper & 128 & 1,536 \\
\hline & & Onion & 146 & 1,752 \\
\hline
\end{tabular}

\section{Source field survey 2015}


Int.J.Curr.Res.Aca.Rev.2016; 4(11):87-98

Table.2 Monthly and annual demand for 'large' categories

\begin{tabular}{|c|c|c|c|c|}
\hline Large category & Number & Vegetables & $\begin{array}{l}\text { Monthly } \\
\text { Volumes } \\
\text { (Kg) }\end{array}$ & $\begin{array}{c}\text { Yearly } \\
\text { Volumes } \\
(\mathrm{Kg})\end{array}$ \\
\hline \multirow[b]{4}{*}{ Hotels/ Guesthouses } & \multirow[b]{4}{*}{2} & Onion & 146 & 1,752 \\
\hline & & Tomatoes & 255.5 & 3,066 \\
\hline & & Chili pepper & 16 & 192 \\
\hline & & Cabbage & 175 & 2100 \\
\hline \multirow[b]{5}{*}{ Restaurants/chopbars } & \multirow[b]{5}{*}{3} & Onion & 182.5 & 2,190 \\
\hline & & Tomatoes & 364 & 4,368 \\
\hline & & Fresh Okra & 1,980 & 23,760 \\
\hline & & Chilli pepper & 36 & 432 \\
\hline & & Cabbage & 75 & 900 \\
\hline \multirow[b]{3}{*}{ Boarding Institutions } & \multirow[b]{3}{*}{2} & Onion & 146 & 1,752 \\
\hline & & Chilli pepper & 128 & 1,536 \\
\hline & & Dry okra & 120 & 1,440 \\
\hline
\end{tabular}

Source; field survey, 2015

Table.3 Monthly and yearly demand for vegetables for the 'medium' end users

\begin{tabular}{|c|c|c|c|c|}
\hline Medium Category & $\begin{array}{l}\text { Number of hotels } \\
\text { in category }\end{array}$ & Vegetables & $\begin{array}{l}\text { Monthly Volume } \\
\text { (Kg) }\end{array}$ & $\begin{array}{l}\text { Estimated Annual } \\
\text { Volumes (Kg) }\end{array}$ \\
\hline \multirow[b]{5}{*}{$\begin{array}{c}\text { Hotels/ Guest } \\
\text { houses }\end{array}$} & \multirow[t]{5}{*}{ 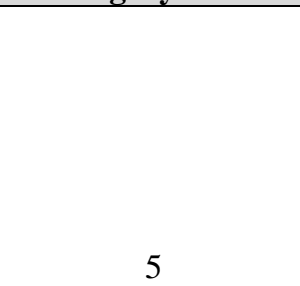 } & Onion & 365 & 4,380 \\
\hline & & Tomatoes & 260 & 3,120 \\
\hline & & Fresh Okra & 150 & 1800 \\
\hline & & Chilli pepper & 30 & 360 \\
\hline & & Cabbage & 312 & 3,750 \\
\hline \multirow[b]{4}{*}{$\begin{array}{c}\text { Restaurant/chop } \\
\text { bars }\end{array}$} & \multirow[b]{4}{*}{5} & Onion & 340 & 4,080 \\
\hline & & Tomatoes & 520 & 6,240 \\
\hline & & Fresh Okra & 150 & 1,800 \\
\hline & & Chillli pepper & 40 & 480 \\
\hline \multirow{3}{*}{$\begin{array}{l}\text { Boarding } \\
\text { Institutions }\end{array}$} & \multirow{3}{*}{5} & Onion & 365 & 4,380 \\
\hline & & Chillli pepper & 160 & 1,920 \\
\hline & & Dry okra & 300 & 15,600 \\
\hline
\end{tabular}

Source; field survey, 2015 
Table.4 Vegetable profiling in the Upper East Region

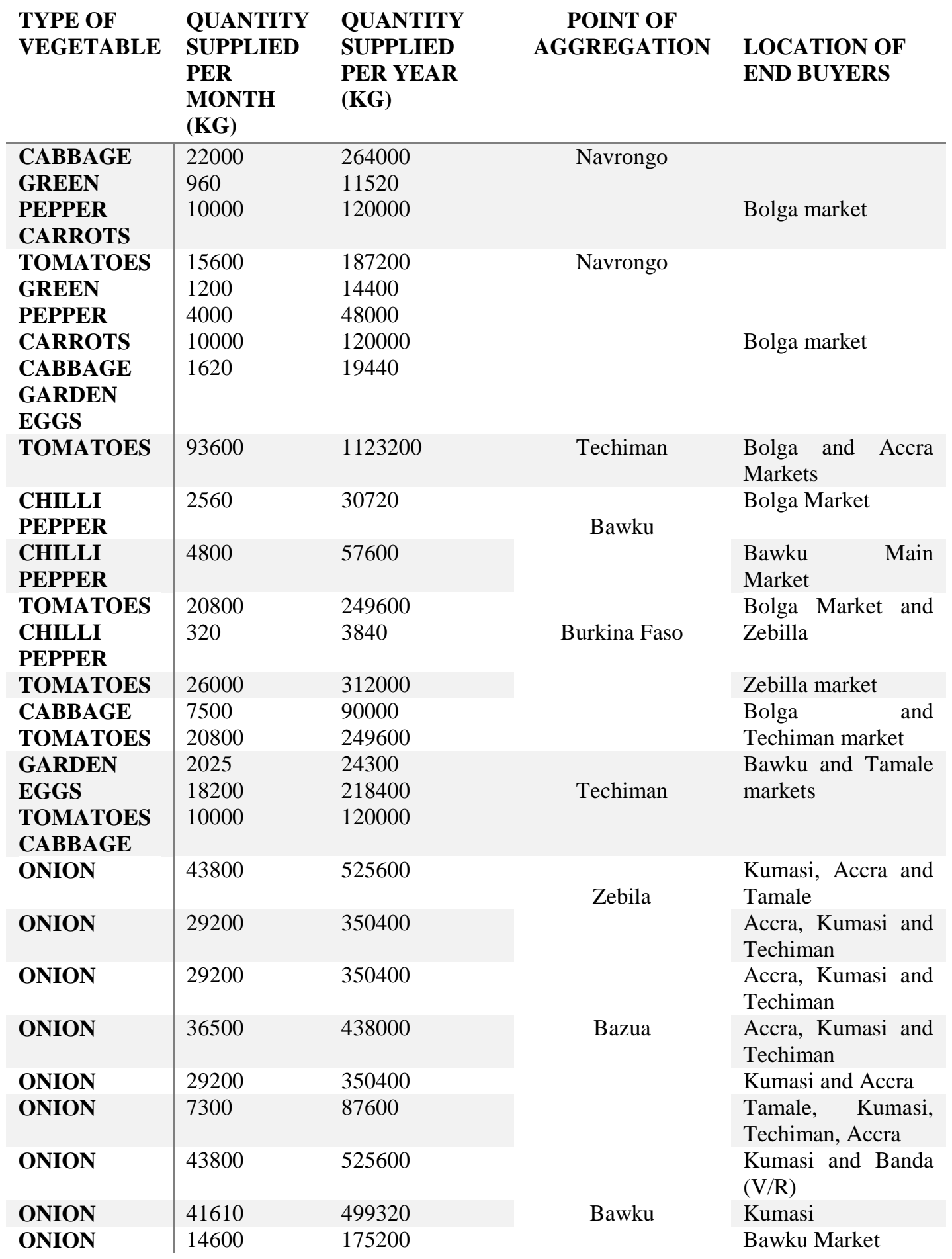


Int.J.Curr.Res.Aca.Rev.2016; 4(11):87-98

Fig.1 Vegetables aggregated and consumed in the Upper East Region of Ghana

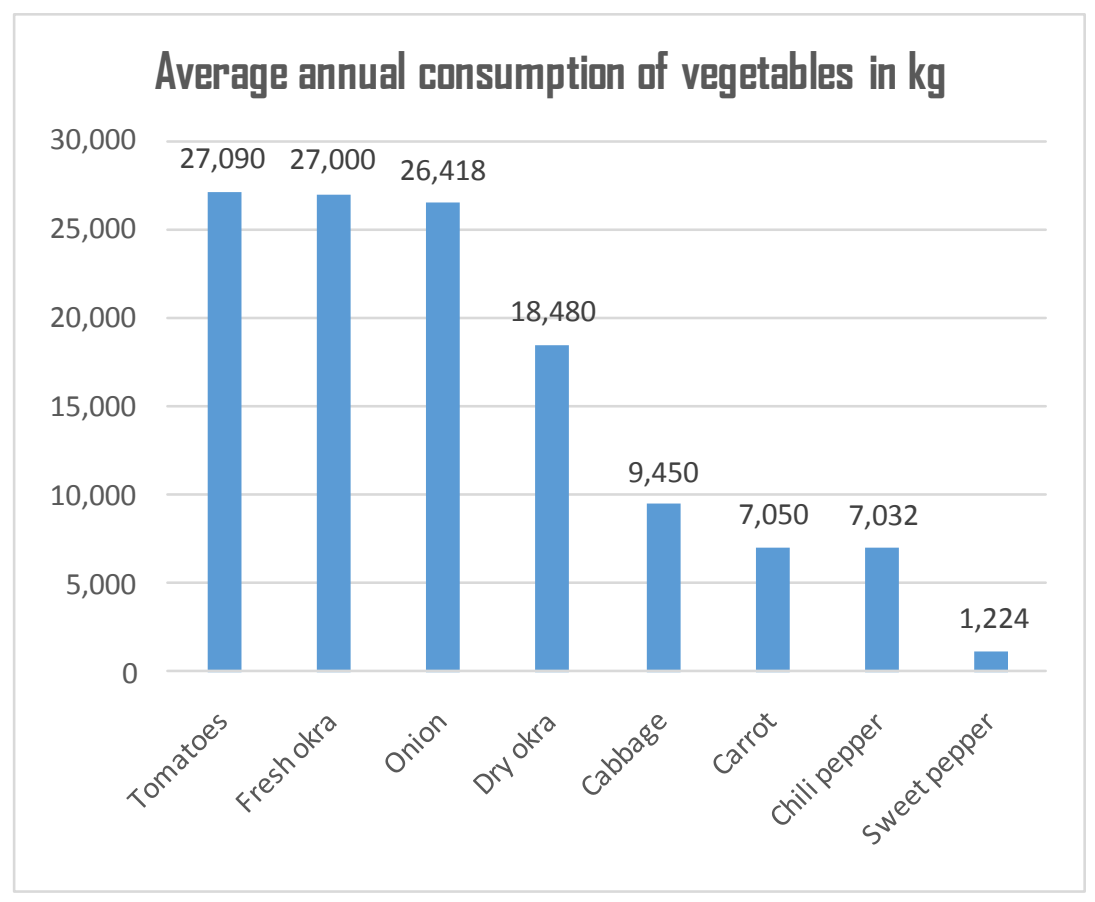

Fig.2 Mode of transporting vegetables

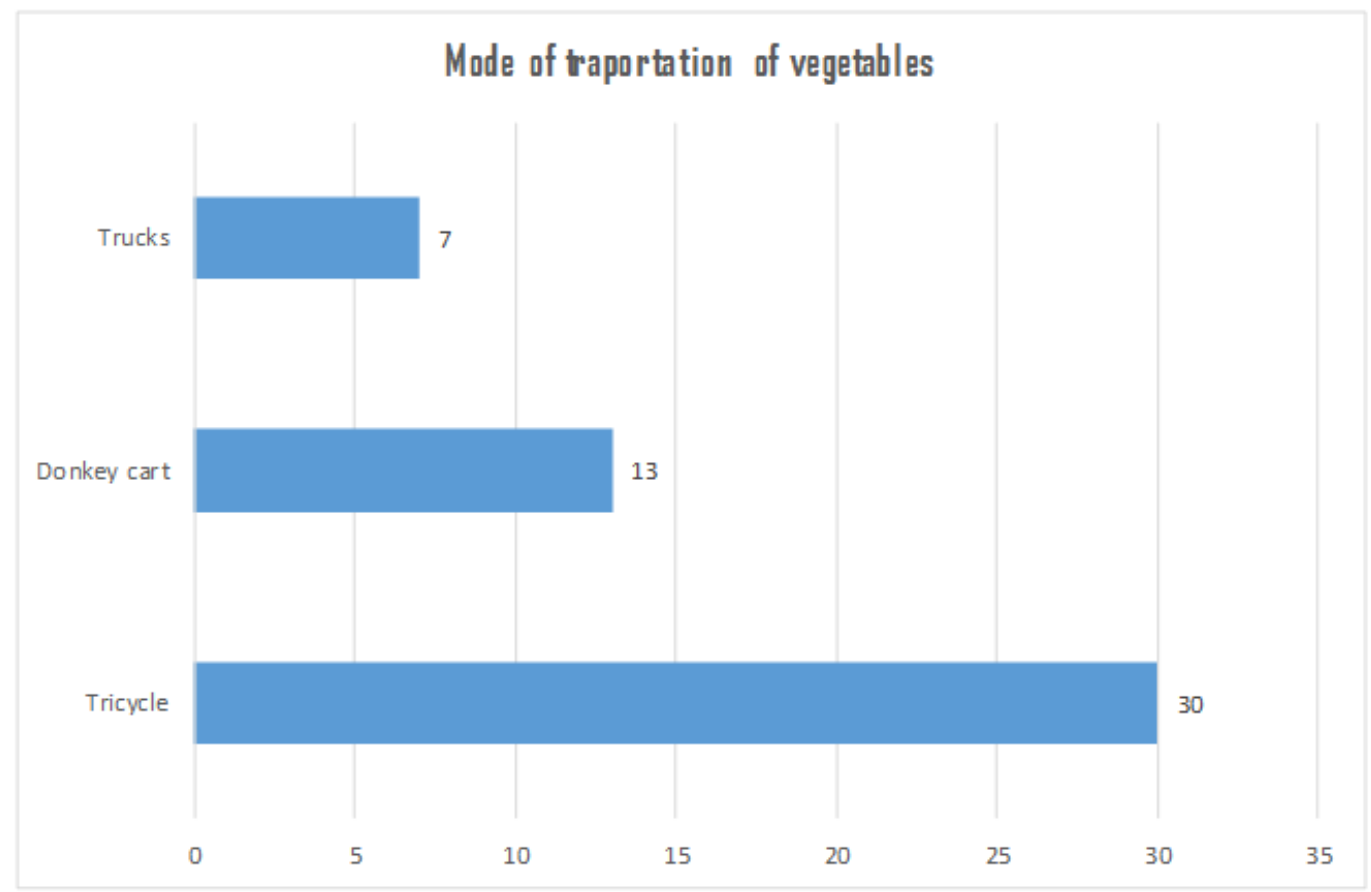


Int.J.Curr.Res.Aca.Rev.2016; 4(11):87-98

Fig.3 Modes of storageof vegetables

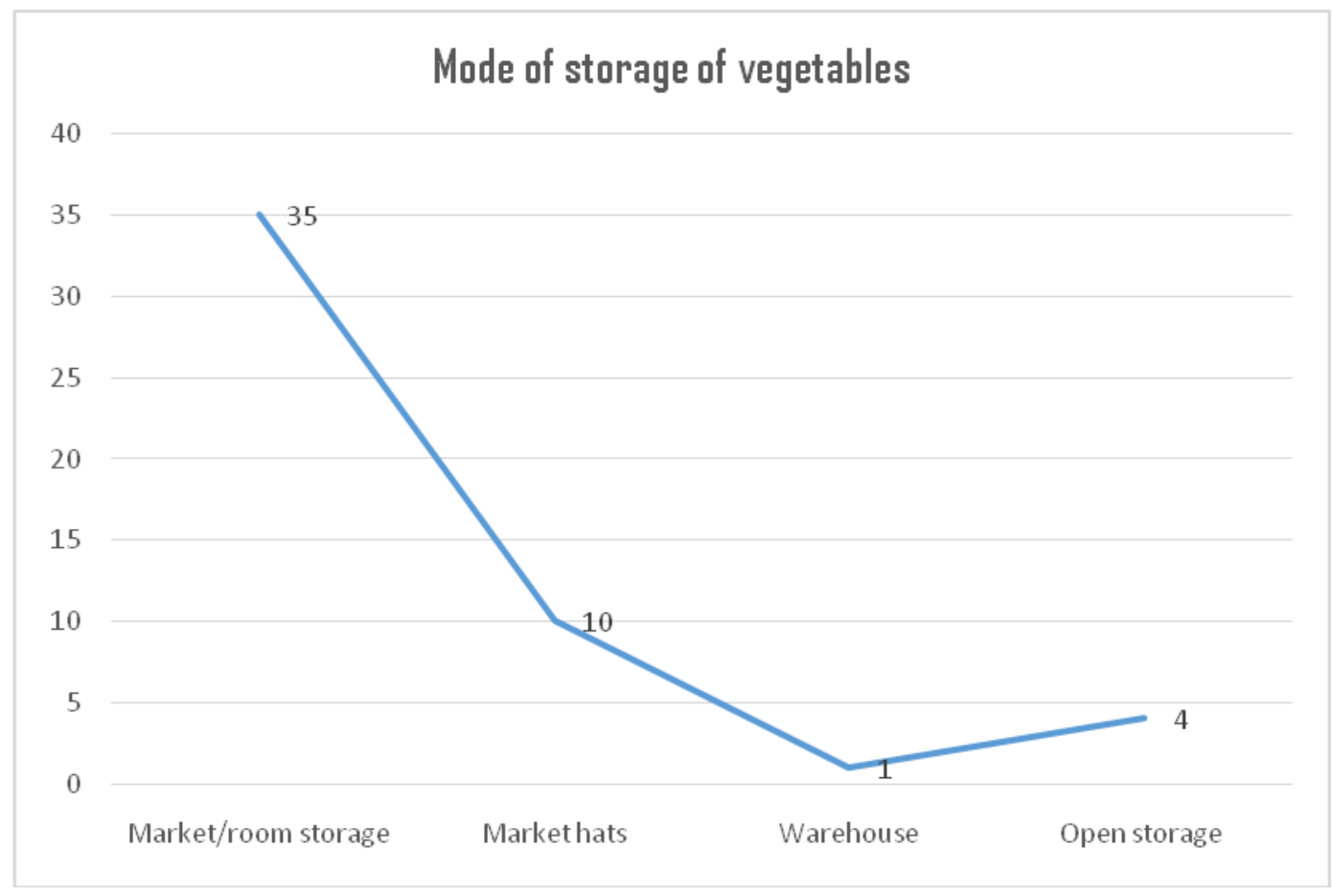

Fig.4 Challenges of aggregation and marketing of vegetables

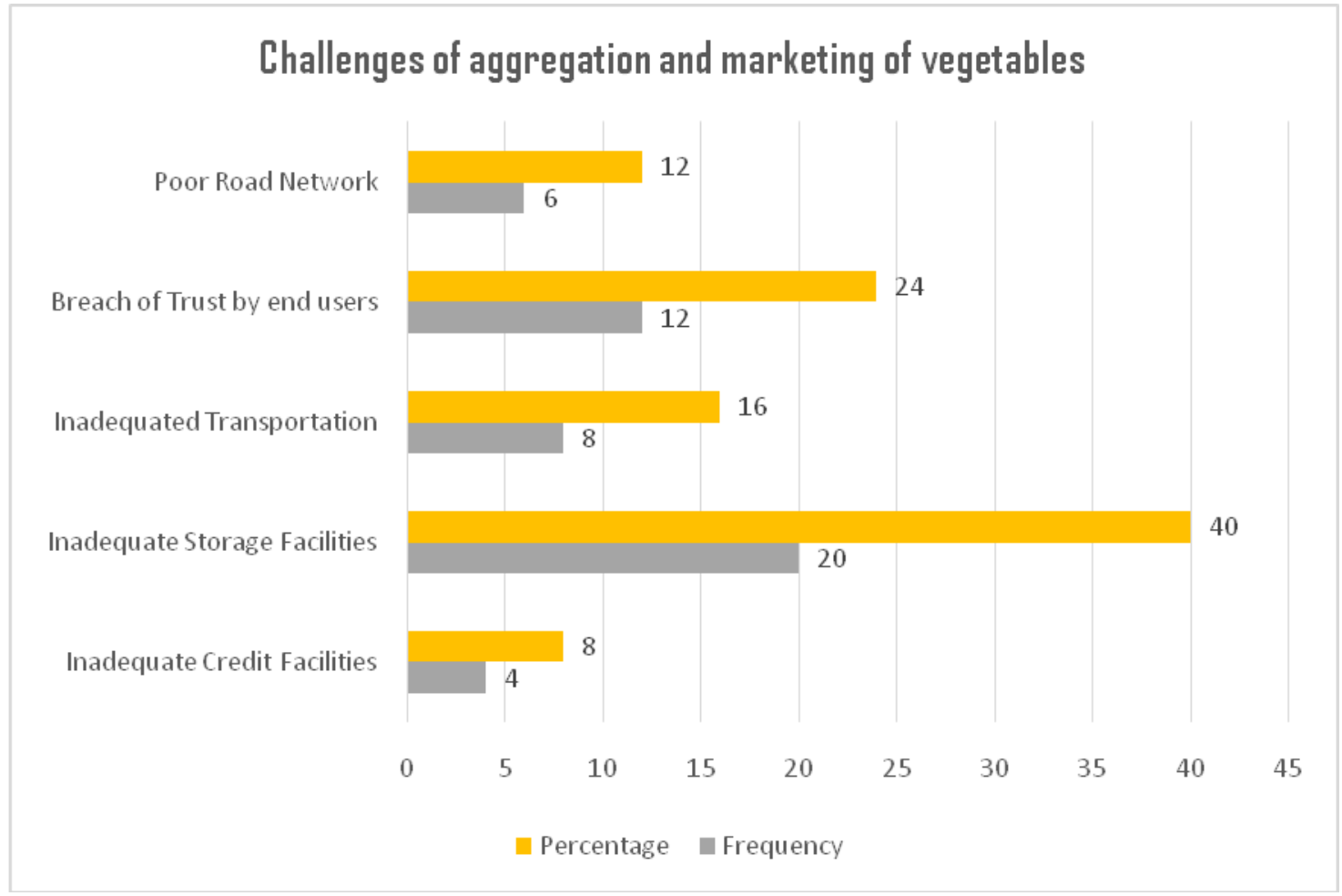


It is further highlighted that there were potential buyers (end users) of vegetables in the region with the capacity of buying vegetables in large quantities. These end users are credit worthy as their locations can serve as collateral if they choose to buy on credit.

The vegetable business in the Upper East Region of Ghana promise high prospects in future, with the capacity of adequate supply across all regions of the country, in particular and the export market, in general. Notwithstanding, actors in the value chain have to grapple with the constraints of finance and storage facilities.

\section{References}

Abbot, J.C. 1984. FAO marketing Guide Number 1. Marketing problems and Improvements.

Antwi, M., Seahlodi, P. 2011. Marketing Constraints Facing Emerging SmallScale Pig Farmers in Gauteng Province, South Africa. J. Human Ecol., 36(1): 37-42

Balarane, A. and Oladele, O.I. 2012. Awareness and use of agricultural market information among small scale farmers in Ngaka Modiri Molema District of North West Province. Life Sci. J., 9(3): 57 - 62
Danso, G., Fialor, S.C., Drechsel, P. 2002b. Perceptions of organic agriculture by urban vegetable farmers and consumers in Ghana. Urban Agricultural Magazine, 6: 23-24.

Kwarteng, J.A. and Towler, M.J. 1994. West African Agriculture: A Textbook for School and College. London: Macmillan.

Matsane, S.H., Oyekale, A.S. 2014. Factors affecting marketing of vegetables among small-scale farmers in Mahikeng local municipality, North West Province, South Africa. Mediterranean J. Social Sci., Vol. 5(20), Pp 390-397.

MOFA. 2014. Statistics, Research and Information Directorate (SRID) Ministry of food and Agriculture, 67p

Senyolo, G.M., Chaminuka, P, Makhura, M.N and Belete, A. 2009. Patterns of access and utilization of output markets by emerging farmers in South Africa: Factor analysis approach. African J. Agri. Res., 4(3): 208-214.

Tita, D.F. 2008/9. A transaction cost analysis of factors affecting market arrangements in the agroforestry tree product value chain in Cameroon. Internet file retrieved on 31st March 2013

from: http://www.worldagroforestry.org/dow nloads/ publications/PDFs/ B16462.PDF

\section{How to cite this article:}

Ninfaa, A.D., D. Oppong-Sekyere, A-R.S. Salifu, B.B. Yintii and Manamzor, F.L. 2016. An Assessment of the Performance of Some Vegetable Markets and End Users in the Upper East Region of Ghana. Int.J.Curr.Res.Aca.Rev.4(11): 87-98. doi: http://dx.doi.org/10.20546/ijcrar.2016.411.013 